\title{
Diálogos sobre sexualidade na escola: uma intervençáo possível
}

\author{
Talking about sexuality in school: a possible intervention
}

\author{
Raquel de Andrade Souza Ew ${ }^{\mathrm{I}}$ \\ Jaqueline Conz ${ }^{\text {II }}$ \\ Aline Daniela Gonçalves de Oliveira Farias III \\ Paula Biazetto Machado Sombrio ${ }^{\text {IV }}$ \\ Kátia Bones Rocha ${ }^{\mathrm{V}}$
}

\section{Resumo}

O objetivo desta intervenção foi implementar oficinas sobre sexualidade em escolas, fundamentadas na metodologia participativa. Foram realizadas 11 oficinas em Porto Alegre, com 349 alunos, organizadas a partir das dúvidas dos adolescentes. As oficinas visaram promover reflexão crítica e autocuidado. Mapearam-se os sentidos associados à palavra sexualidade e as principais dúvidas dos jovens. As palavras mais referidas foram: sexo, amor, camisinha, prazer, gênero, homem, mulher, gravidez, doenças e relação. As dúvidas mais frequentes foram: primeira relação sexual, gravidez, cuidados médicos, sexo e drogas, gênero, orientaçáo sexual, cultura e sexualidade, corpo e prazer, infecçóes sexualmente transmissíveis e violência. Os alunos avaliaram a intervenção positivamente. Os resultados apontam para necessidade de as escolas abordarem o tema da sexualidade, construindo espaços de diálogo.

Palavras chave: Sexualidade; Escola; Oficinas; Prevenção.

\section{Abstract}

The aim of this intervention was to implement workshops on sexuality in schools, based on participant methodology. We performed 11 workshops in Porto Alegre with 349 students, organized from the students' questions. The workshops aimed to promote critical reflection and self-care. We mapped the meanings related to sexuality and the students' main doubts. The most cited words were: sex, love, condom, pleasure, gender, man, woman, pregnancy, diseases, and relationship. The most frequent doubts were: first sexual intercourse, pregnancy, medical care, sex and drugs, gender, sexual orientation, culture and sexuality, body and pleasure, sexually transmitted infections, and violence. Students assessed the intervention positively. Results point to the need for schools to approach the theme of sexuality, building spaces of dialogue.

Keywords: Sexuality; School; Workshops; Prevention.

\footnotetext{
${ }^{\mathrm{I}}$ Doutoranda em Psicologia Social pela Pontifícia Universidade Católica do Rio Grande do Sul. Integrante do Grupo de Pesquisa Psicologia, Saúde e Comunidades do Programa de Pós-Graduação da Faculdade de Psicologia da PUCRS. raquelew@hotmail.com

${ }^{\text {II }}$ Mestre em Psicologia Social pela Pontifícia Universidade Católica do Rio Grande do Sul. Integrante do grupo de pesquisa Psicologia, Saúde e Comunidades do Programa de Pós-Graduação da Faculdade de Psicologia da PUCRS. jaqueconz@gmail.com

III Psicóloga pela Pontifícia Universidade Católica do Rio Grande do Sul. Integrante do grupo de pesquisa Psicologia, Saúde e Comunidades do Programa de Pós-Graduação da Faculdade de Psicologia da PUCRS. aline.daniela@acad.pucrs.br

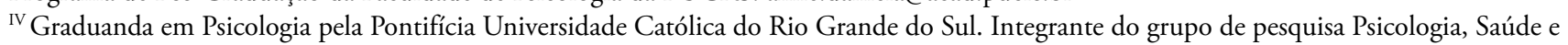
Comunidades do Programa de Pós-Graduação da Faculdade de Psicologia da PUCRS. paula.biazetto@gmail.com

${ }^{\vee}$ Doutora em Psicologia pela Universidade Autônoma de Barcelona.Professora no Programa de Pós-Graduação em Psicologia da PUC-RS.

Coordenadora do Grupo de Pesquisa Psicologia, Saúde e Comunidades na PUC-RS. katiabonesrocha@gmail.com
}

A temática da sexualidade é muitas vezes entendida como algo "natural", como dado pela natureza, inerente ao ser humano (Louro, 2013). Assim, como afirma Louro (2013), esta concepção está ancorada na premissa de que todos vivemos nossos corpos universalmente da mesma maneira. No entanto, podemos entender que a vivência da sexualidade envolve processos sociais, culturais e históricos, nos quais marcadores como idade, raça/etnia, nacionalidade, classe social e orientação sexual apontam para uma pluralidade de possibilidades.

No contexto brasileiro, a temática da sexualidade vem sendo abordada com restriçóes, calcada em aspectos reprodutivos e funcionais, especialmente no contexto escolar. As questóes referentes aos aspectos motivacionais, comportamentais e psicológicos envolvidos com as práticas sexuais e relacionais têm sido, muitas vezes, relegadas ao tabu, encontrando resistências e dificuldades de abordagem pelos profissionais da educação.

Os professores reconhecem a educaçáo sexual como um importante aspecto dentro do processo de formaçáo dos estudantes. Entretanto, muitas vezes os professores não se sentem seguros ao abordar questôes de sexualidade dentro da escola (Figueiró, 2006). Entre os receios mais comuns estáo a forma como os pais encaram essa interferência, os choques de valores e crenças embutidos no tema da sexualidade e o poder de influenciar a vida sexual de seus alunos. Segundo os 
dados presentes nas Diretrizes Nacionais para a Atenção Integral à Saúde de Adolescentes e Jovens na Promoção, Proteção e Recuperação da Saúde (Brasil, 2010), as meninas brasileiras iniciam a atividade sexual entre os 12 anos e os 16 anos e os meninos entre os 15 e os 17 anos de idade, não havendo diferenças regionais, sociais ou de cor (Brasil, 2010).

Tanto a sexualidade como as questóes referentes à exposição às Infecçôes Sexualmente Transmissíveis (IST) ainda se constituem em temáticas que precisam ser esclarecidas junto à população e, em especial, aos jovens que estáo iniciando ou em plena atividade sexual. No Brasil, houve um aumento expressivo no número de casos de aids em jovens de 15 a 24 anos na última década, que triplicou de 2006 para 2015 (Brasil, 2016).

Além do aumento específico entre jovens, Porto Alegre apresenta dados alarmantes em comparaçáo com outros estados brasileiros. A capital gaúcha apresentou a maior taxa entre as capitais brasileiras de detecçâo de aids em 2014, com 74 casos para cada 100 mil habitantes, apresentando também o maior coeficiente de mortalidade (23,7 para cada 100 mil habitantes) (Brasil, 2016). Mais de $40 \%$ de todas as novas infecçóes da América Latina estão concentradas no Brasil. Na América Latina, , os adultos jovens estão desproporcionalmente mais vulneráveis ao HIV (UNAIDS, 2016).

A ausência de um espaço aberto para discussões sobre assuntos relacionados à sexualidade, aliada à falta de conhecimento ou informaçóes distorcidas sobre o tema, agravam a vulnerabilidade dos adolescentes e prejudicam tomadas de decisão, levando-os a iniciar a vida sexual sem proteção, sujeitando-se a uma gravidez indesejada ou estando expostos às IST (Mantovani, Tres, Silva \& Moura, 2014). De acordo com Tonelli (2004), os jovens têm direito ao acesso a informaçóes e educaçáo em saúde sexual e saúde reprodutiva, assim como de adquirir métodos e meios que os auxiliem a evitar uma gravidez não planejada e prevenir-se contra as IST, respeitando sua liberdade de escolha.

Cabe destacar que a educaçáo sexual não deve partir da premissa prescritiva de práticas sexuais certas ou erradas (Figueiró, 2006; Paiva, 2000). A grande contribuição da escola e das equipes formadoras é produzir um espaço de reflexão sobre as diversas formas de viver a sexualidade, baseado no respeito às diferenças, aos outros e a si mesmo. Nesse sentido, oficinas de educaçáo sexual nas escolas pretendem trazer a questão da sexualidade à tona, produzindo espaços de interação entre pares e professores, partindo da premissa que os alunos já possuem conhecimento prévio sobre a sexualidade. A partir desse conhecimento, docentes e discentes podem estabelecer uma construção em conjunto, fazendo um alinhamento entre os seus próprios valores e as novas informaçóes acessadas, dando singularidade a sua compreensão da sexualidade e das futuras tomadas de decisão. O objetivo não é dar respostas, mas sim, facilitar e estimular o diálogo sobre o tema (Paiva, 2000).

A escola pode ser um espaço protetivo para os adolescentes, mesmo em contextos sociais de maior vulnerabilidade. Assim, o contexto escolar pode ser um local potente para pensar em intervençóes que busquem diminuir as desigualdades em saúde, pois, além de ser um espaço de convivência, acaba por ser parte constituinte de subjetividade. A escola pode possibilitar aos jovens construir conceitos sobre o mundo, formalizando conhecimentos e critérios para o processo decisório das inúmeras questóes referentes ao seu cotidiano. Sendo, portanto, um lugar profícuo para as oficinas servirem de instrumentos relevantes para promoção de reflexão.

Alguns autores ressaltam a necessidade do desenvolvimento de estratégias de educação que possibilitem associar a informação à reflexão, oportunizando ao jovem a manifestação de suas ideias, vivências e sentimentos, para que possa exercer um olhar crítico e uma prática transformadora, com oportunidades de mudança de comportamentos e atitudes que minimizam riscos (Jeolás \& Ferrari, 2003; Martins \& Souza 2013) e que possibilitem uma vivência mais prazerosa de sua sexualidade. Nota-se a importância de intervençôes por meio de oficinas sobre sexualidade, considerando que esse método favorece a construçáo de espaços de discussão, troca de experiências individuais e grupais, partindo da realidade para a reflexão e debates de práticas (Camargo \& Ferrari, 2009). De acordo com Freitas e Dias (2010), a prática pedagógica de oficinas propicia a exposição de ideias, conceitos e experiências sem julgamentos, facilitando a transformação de preconceitos pela via reflexiva e de socialização de saberes e de experiências.

Assim, o objetivo desta intervenção foi implementar oficinas sobre sexualidade nas escolas, a partir das dúvidas apresentadas pelos adolescentes. Além disso, procurou-se mapear os sentidos e significados relacionados à palavra sexualidade, bem como as principais dúvidas apontadas pelos participantes. Para finalizar, foi avaliada a percepção dos alunos sobre a intervenção realizada.

\section{MÉTODO}

As oficinas realizadas nas escolas se fundamentam na metodologia participativa, em que se compreendem os participantes como sujeitos ativos. Essa metodologia 
possibilita a reflexão pessoal, interpessoal e de ensinoaprendizagem, promovendo integração, vínculos afetivos e respeito no grupo. Além disso, proporciona ponderação crítica, conscientização e ressignificação de valores, emoçôes e conhecimentos (Silva, 2002; Moskovics \& Calvetti, 2008).

A oficina consistiu em um encontro com duração de cerca de duas horas, com a presença dos alunos e de representantes docentes. Ao todo, foram realizadas 11 oficinas em quatro escolas, três públicas e uma privada, totalizando 349 alunos. O objetivo inicial era promover as oficinas em três escolas públicas e três privadas, mas somente uma escola privada aceitou participar do projeto. Esse fato é importante, tendo em vista que os debates sobre sexualidade e gênero nas escolas enfrentam um cenário de resistência e restriçóes, sob a égide de que silenciar é a melhor forma de não "estimular" a sexualidade e comportamentos tidos como indesejáveis nos jovens.

\section{Descrição e Sistematização da Intervenção}

O trabalho iniciou a partir do contato telefônico com sete escolas para agendamento de reunióes com os coordenadores pedagógicos, todas estas escolas já haviam desenvolvido alguma parceria com a Pontifícia Universidade Católica do Rio Grande do Sul - PUCRS. $\mathrm{O}$ objetivo era apresentar a proposta das oficinas de sexualidade a serem executadas. Das sete escolas contatadas, cinco aceitaram realizar a intervenção.

Posteriormente, foi solicitado que as escolas explicassem a intervenção para os alunos e disponibilizassem uma caixa fechada na qual estes poderiam depositar dúvidas sobre a temática sexualidade de forma anônima, o que foi realizado por todas as escolas participantes. Segundo Moizés e Bueno (2010), toda ação com adolescentes deve começar com as dúvidas e temáticas que surgem a partir deles, considerando, além das informaçóes, o debate sobre as atitudes dos sujeitos diante da sexualidade. Essas perguntas serviram de base para a construção da intervenção e foram posteriormente categorizadas por afinidade de conteúdo, em blocos temáticos que eram trabalhados durante as oficinas.

$\mathrm{Na}$ organização da intervenção participaram estudantes de doutorado, mestrado e de iniciação científica do curso de Psicologia da PUCRS. A equipe de oficineiras/os era constituída por 10 integrantes, cisgênero, de diferentes orientaçóes sexuais, com faixa etária entre 19 e 45 anos. Todos os oficineiras/os participaram em algum momento do processo de organização das perguntas e construção das oficinas. As intervençôes sempre contaram com a participaçáo de pelo menos quatro integrantes (um de doutorado, um de mestrado e dois de iniciação científica).

Cada intervenção contemplou cinco etapas sistematizadas na Figura 1, que apresenta o fluxo da oficina e que, na sequência, serão descritas.

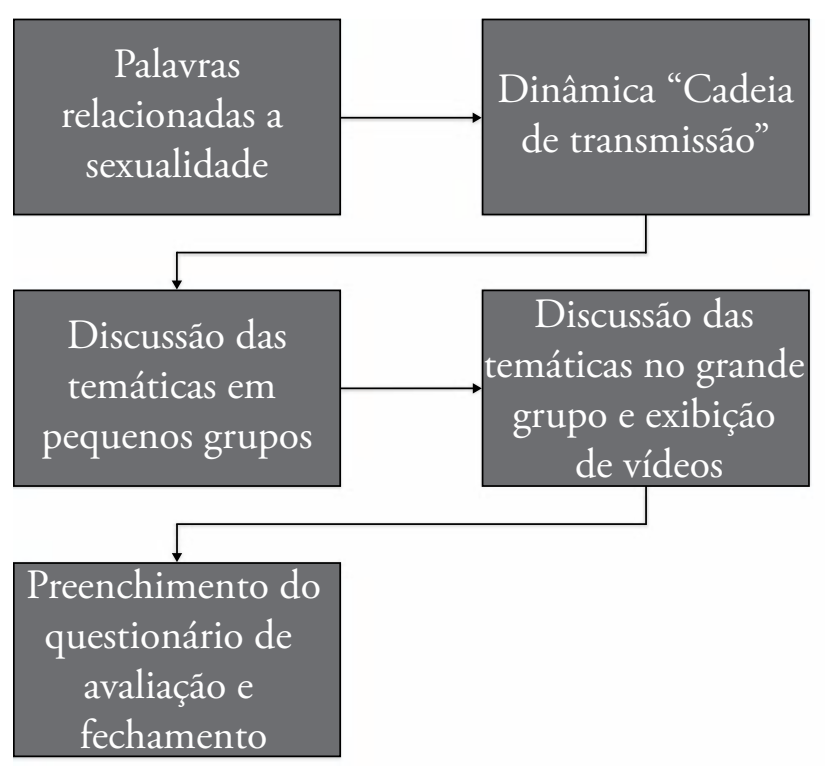

\section{Figura 1}

\section{Sistematização da intervenção}

A primeira atividade da oficina consistiu em um momento em que os alunos escreviam palavras que associavam com "sexualidade" em uma folha em branco, de forma anônima. Essas palavras foram posteriormente recolhidas e, via análise de conteúdo (Bardin, 1977), foram agrupadas de acordo com sua frequência, levando em conta quais palavras foram mais mencionadas pelos alunos. No total foram referidas 339 palavras diferentes, dentre as quais se destacam sexo $(\mathrm{n}=154)$, amor $(\mathrm{n}=86)$, camisinha $(\mathrm{n}=53)$, prazer $(\mathrm{n}=51)$, gênero $(\mathrm{n}=26)$, homem $(n=23)$, mulher $(n=22)$, gravidez $(n=21)$, doenças $(n=20)$ e relação $(n=20)$.

A partir destes resultados as autoras elaboraram uma nuvem de palavras, com o apoio do software NVivo. O resultado é apresentado na Figura 2:

$\mathrm{Na}$ sequência, foi realizada a dinâmica nomeada "Cadeia de Transmissão", em que era distribuída, aleatoriamente, uma folha em branco para cada um dos participantes. Duas delas continham símbolos pequenos: em uma, havia um círculo, que representava a proteção através do uso do preservativo, e, na outra, um asterisco, simbolizando o vírus HIV. Os alunos ainda não possuíam informação sobre o que cada um desses símbolos representava. A orientação dada para a dinâmica era de que os jovens deveriam transitar pela sala durante a execuçáo de uma música e, quando houvesse 
uma interrupção do som, os alunos teriam que autografar/assinar e receber um autógrafo/assinatura de outro colega em sua folha. Tal procedimento foi repetido por cerca de cinco vezes. Ao terminar a quinta rodada de autógrafos, solicitou-se ao aluno com o círculo na folha que permanecesse sentado durante os passos seguintes. Foi pedido para o aluno com o asterisco que se posicionasse em frente ao grupo, e, em sequência, aos que tivessem seu autógrafo na folha para também se dirigirem à frente, e assim sucessivamente. Por fim, somente o aluno com o círculo permanecia sentado.

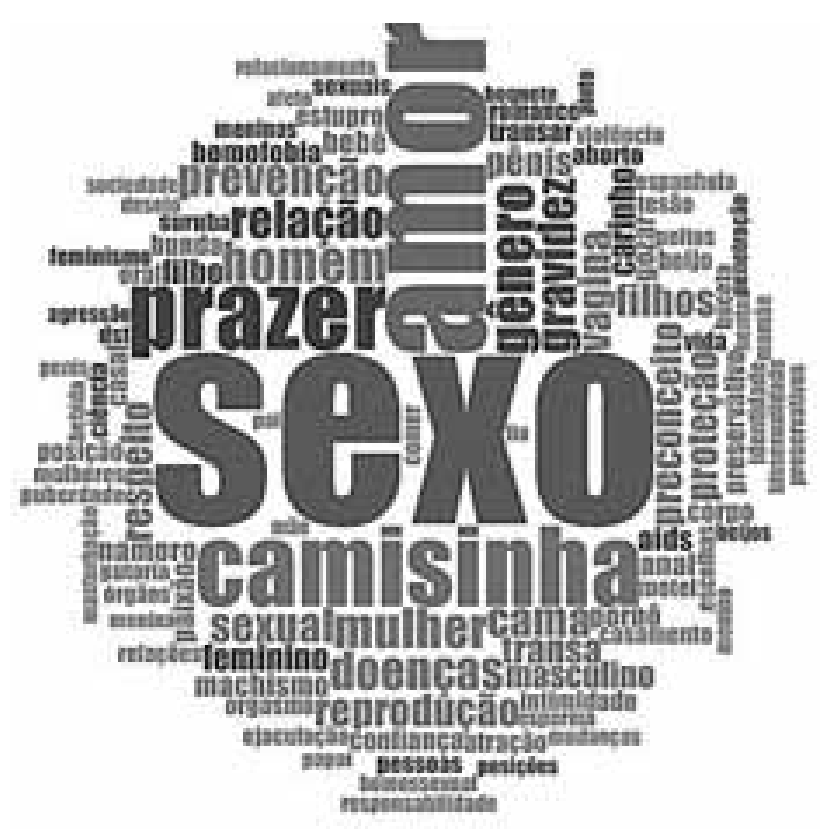

\section{Figura 2}

Nuvem de palavras associadas à sexualidade.

Dessa forma, foi demonstrado o funcionamento de uma cadeia de transmissão do HIV, já que cada autógrafo/assinatura simbolizava uma relação sexual. Foi explicado que apenas aquele/a jovem que usou preservativo (círculo) estava protegido, e que inicialmente apenas uma pessoa portava o vírus HIV (asterisco). À semelhança do que ocorre na realidade, a dinâmica procurou explicitar que, na cadeia de transmissáo, basta apenas uma pessoa não usar preservativo para que todo o grupo de contato esteja sujeito ao risco de infecção. Nesse momento, foram apresentados dados epidemiológicos do Rio Grande do Sul e, especialmente, da cidade de Porto Alegre, demonstrando o quanto essa cadeia de transmissão estava presente no cotidiano de todos.

Apesar da dinâmica contemplar também os aspectos biológicos do processo de transmissão do HIV/aids, sua escolha deve-se pela facilidade de aplicação, clareza na demonstração da cadeia de transmissão e viabilização para abordagem de aspectos emocionais e sociais que se interpóe nas relações. A música utilizada na intervenção e a atmosfera festiva que se produzia, permitia um momento de integração e descontração, que servia como um disparador para iniciar a conversa sobre sexualidade, preconceito, crenças e tabus presentes na sexualidade.

Assim, após a dinâmica partiu-se para questôes enviadas previamente pelos alunos. Cada oficina tinha perguntas específicas elaboradas de acordo com as dúvidas dos estudantes. As perguntas, analisadas em conjunto neste estudo, foram reunidas em blocos temáticos comuns e projetadas conforme os seguintes temas: primeira relação sexual, gravidez, cuidados médicos, sexo e drogas, relações de gênero, orientação sexual, cultura e sexualidade, corpo e prazer, infecçôes sexualmente transmissíveis (IST) e violência. Por um lado, o planejamento da intervenção tinha como objetivo falar da sexualidade de forma aberta, sensível e positiva, não restrita a questóes informativas e a doenças. Por outro lado, pretendia informar sobre questóes associadas também ao HIV e outras IST, caso isso aparecesse nas dúvidas dos estudantes. Neste sentido, a partir das perguntas enviadas foi possível trabalhar diferentes aspectos da sexualidade, considerando seus aspectos individuais, sociais, culturais e históricos.

Destaca-se que a atividade era organizada a partir das perguntas dos estudantes, logo os blocos temáticos náo se repetiam na íntegra em todas as oficinas. $\mathrm{Na}$ Figura 3 estáo exemplificadas algumas perguntas formuladas pelos alunos:

Para discussão das dúvidas, os estudantes se reuniram em pequenos grupos, enquanto as/os oficineiras/os circulavam pela sala dialogando com os alunos, com o intuito de atuarem como facilitadores no desenvolvimento da atividade. A aproximaçáo ocorria de maneira informal, interessada e amigável como forma de estimular a reflexão. Para ilustração, estudantes falavam sobre o quanto a primeira relaçáo sexual poderia ser dolorosa e desconfortável. Neste momento, indagaram a oficineira sobre a veracidade desta situação, que respondeu através da metáfora do sapato novo de festa. A oficineira referiu que a primeira relação sexual poderia ser pensada como um sapato de festa com o qual não estamos acostumados. Se o colocarmos de qualquer jeito e sairmos correndo ou dançando a noite toda, sem prévia adaptação e conhecimento, é possível que ele nos machuque. Por outro lado, se colocamos o sapato de forma gentil e sem forçar nossos limites, conhecendo nossos próprios pés e o sapato, é possível que exista esta aproximação e na experiência o que vai 
se destacar será o quanto a festa foi prazerosa. Assim ocorreram as conversas, no formato de interlocução direta através de questionamentos multidirecionais que poderiam envolver questóes relacionadas à escola, familiares, amigos, sociedade e cada um. Logo após a discussão nos pequenos grupos, o debate era aberto ao grande grupo para manifestação espontânea do que pensaram sobre as questóes.

\begin{tabular}{|c|c|}
\hline Temáticas & Perguntas \\
\hline \multirow{2}{*}{ Primeira vez } & É comum sangrar e doer na primeira vez? \\
\hline & Sou virgem e me julgam, por que? \\
\hline \multirow[t]{2}{*}{ Gravidez } & $\begin{array}{l}\text { Qual a probabilidade de engravidar, transando sem camisinha e tomando } \\
\text { anticoncepcional? }\end{array}$ \\
\hline & É possível engravidar sem penetração ou ejaculando à distância? \\
\hline \multirow[t]{2}{*}{ Cuidados Médicos } & O que é fimose? \\
\hline & Por que mulher tem corrimento? \\
\hline \multirow{2}{*}{ Sexo e Drogas } & Por que o homem sob efeito do álcool demora para ejacular? \\
\hline & Drogas (maconha, álcool) podem influenciar no desempenho sexual? \\
\hline \multirow{2}{*}{ Relações de gênero } & Quantas vezes a menina tem que dar para ser considerada puta pelos homens? \\
\hline & Por que a maioria das gurias acham que os guris só pensam em sexo? \\
\hline \multirow[t]{2}{*}{ Orientação sexual } & $\begin{array}{l}\text { Se eu tenho interesse por gurias e também por guris, será que sou gay? Será que sou } \\
\text { bi? }\end{array}$ \\
\hline & Por que muitos julgam sua sexualidade, se não é crime ser diferente? \\
\hline \multirow{2}{*}{ Cultura e sexualidade } & Por que o prazer é tido como algo ruim em nossa sociedade? \\
\hline & Como falar sobre sexualidade com amigos e familiares? \\
\hline \multirow[t]{2}{*}{ Corpo e prazer } & Por que nos masturbamos? \\
\hline & Como chegar ao orgasmo? \\
\hline \multirow[t]{2}{*}{ ISTs e HIV } & $\begin{array}{l}\text { Fazer sexo sem proteção pode facilitar para contrair uma doença? Mesmo que o } \\
\text { parceiro náo tenha HIV? }\end{array}$ \\
\hline & É possível se transmitir alguma doença pelo beijo na boca? \\
\hline Violência & Por que a maioria dos estupros são realizados por familiares? \\
\hline
\end{tabular}
Figura 3

Temas e perguntas abordados nas oficinas

Fonte: Elaboração própria

Foram utilizados alguns disparadores visuais em momentos específicos da oficina, como complemento e esclarecimento sobre o tema. Ao ser abordado o tópico sobre métodos contraceptivos, foi exibido um vídeo sobre o correto manuseio e uso dos preservativos feminino e masculino. É importante mencionar que muitos jovens não sabiam sobre o uso correto dos preservativos. Durante o bloco de IST e HIV/aids, apresentou-se um vídeo aprovado pelo Ministério da Saúde. Esse audiovisual (Rocha $\&$ Pizzinato, 2015) consiste em um recorte das principais barreiras psicossociais que impedem as pessoas de procurarem um serviço de saúde para a identificação do seu estado sorológico. Também apresenta as facilidades encontradas nos serviços de saúde e onde as pessoas podem realizar os testes rápidos de HIV, Sífilis e Hepatites Virais.

Ao final da oficina, os alunos e os representantes docentes preencheram um questionário de avaliação da intervenção em formato de escala Likert de quatro pontos, desde as opçóes concordo plenamente até discordo. A avaliaçáo contemplou os assuntos abordados na oficina, a condução por parte dos pesquisadores e o aprendizado obtido, além de contar com uma avaliação global da oficina. As respostas dos estudantes estão descritas na Tabela 1 a seguir: 


\section{Tabela 1}

Resultado do questionário de avaliação da oficina respondido pelos estudantes

\begin{tabular}{|c|c|c|c|c|c|c|c|c|c|}
\hline \multicolumn{2}{|r|}{ Perguntas } & \multicolumn{2}{|c|}{$\begin{array}{c}\text { Concordo } \\
\text { plenamente }\end{array}$} & \multicolumn{2}{|c|}{ Concordo } & \multicolumn{2}{|c|}{$\begin{array}{l}\text { Concordo } \\
\text { em partes }\end{array}$} & \multicolumn{2}{|c|}{ Discordo } \\
\hline & & $\mathbf{N}$ & $\%$ & $\mathbf{N}$ & $\%$ & $\mathbf{N}$ & $\%$ & $\mathbf{N}$ & $\%$ \\
\hline \multirow{3}{*}{$\begin{array}{l}\text { Quanto aos } \\
\text { assuntos } \\
\text { abordados... }\end{array}$} & $\begin{array}{l}\text { Os assuntos foram muito } \\
\text { importantes para mim }\end{array}$ & 159 & 46,2 & 131 & 38,1 & 53 & 15,4 & 1 & 0,3 \\
\hline & $\begin{array}{l}\text { Ainda náo havia conversado sobre esses } \\
\text { temas em atividades promovidas pela escola }\end{array}$ & 84 & 24,7 & 96 & 28,2 & 70 & 20,6 & 90 & 26,5 \\
\hline & $\begin{array}{l}\text { Tinha muitas dúvidas relacionadas } \\
\text { aos temas apresentados }\end{array}$ & 68 & 20,2 & 91 & 27 & 126 & 37,4 & 52 & 15,4 \\
\hline \multirow{6}{*}{$\begin{array}{c}\text { Quanto à } \\
\text { condução } \\
\text { da oficina... }\end{array}$} & $\begin{array}{l}\text { A linguagem utilizada foi adequada } \\
\text { e de fácil compreensáo }\end{array}$ & 247 & 72,2 & 84 & 24,6 & 9 & 2,6 & 2 & 0,6 \\
\hline & $\begin{array}{l}\text { Os convidados deixaram o grupo à } \\
\text { vontade para manifestar suas opiniốes } \\
\text { e contribuir para o debate }\end{array}$ & 248 & 73,8 & 77 & 22,9 & 9 & 2,7 & 2 & 0,6 \\
\hline & $\begin{array}{c}\text { Os convidados demonstraram conhecimento } \\
\text { e segurança na conduçáo da atividade }\end{array}$ & 226 & 66,9 & 88 & 26 & 22 & 6,5 & 2 & 0,6 \\
\hline & $\begin{array}{l}\text { O formato da oficina foi } \\
\text { dinâmico e interessante }\end{array}$ & 184 & 56,1 & 112 & 34,1 & 29 & 8,8 & 3 & 0,9 \\
\hline & $\begin{array}{l}\text { Os filmes utilizados foram } \\
\text { bem esclarecedores }\end{array}$ & 155 & 53,3 & 94 & 32,3 & 32 & 11 & 10 & 3,4 \\
\hline & $\begin{array}{l}\text { Gostei dos métodos utilizados } \\
\text { durante a oficina }\end{array}$ & 189 & 56,9 & 122 & 36,7 & 18 & 5,4 & 3 & 0,9 \\
\hline \multirow{4}{*}{$\begin{array}{c}\text { Quanto ao } \\
\text { aprendizado } \\
\text { com a } \\
\text { oficina... }\end{array}$} & Acho que me deixou mais informado & 214 & 62,2 & 104 & 30,2 & 20 & 5,8 & 6 & 1,7 \\
\hline & Acho que me deixou mais seguro(a) & 155 & 46 & 126 & 37,4 & 40 & 11,9 & 16 & 4,7 \\
\hline & $\begin{array}{l}\text { Acho que me esclareceu sobre } \\
\text { alguns mitos e tabus }\end{array}$ & 162 & 48,5 & 123 & 36,8 & 37 & 11,1 & 12 & 3,6 \\
\hline & $\begin{array}{l}\text { Acho que afetará meu comportamento } \\
\text { de forma positiva }\end{array}$ & 146 & 44,6 & 107 & 32,7 & 48 & 14,7 & 26 & 8 \\
\hline \multirow{2}{*}{$\begin{array}{l}\text { De forma } \\
\text { geral... }\end{array}$} & Gostei de participar da oficina & 230 & 68,5 & 84 & 25 & 16 & 4,8 & 6 & 1,8 \\
\hline & Indicaria para um(a) amigo(a) participar & 178 & 54,6 & 102 & 31,3 & 27 & 8,3 & 19 & 5,8 \\
\hline
\end{tabular}

$\mathrm{Na}$ avaliação da oficina, a maioria dos estudantes $(84,3 \%)$ indicou que os assuntos abordados foram muito importantes. Assim o aprendizado na atividade foi avaliado como um recurso que os deixou mais informados $(92,4 \%)$ e seguros $(83,4)$, permitindo que esclarecessem mitos e tabus $(85,3 \%)$ o que poderá afetar positivamente o seu comportamento (77,3\%). De forma geral, os participantes da oficina assinalaram ter gostado da oficina $(93,5 \%)$ e indicariam a um amigo para participar $(85,9 \%)$ da atividade. Neste sentido, observou-se que a maioria dos alunos estava à vontade para conversar e mostravam-se atentos e curiosos, mesmo diante das diferenças de experiência com os temas dentro dos grupos.

\section{DISCUSSÃO}

A partir dos resultados apresentados percebe-se que parte significativa dos alunos relacionou a palavra sexualidade com sexo. Pode-se dizer que o termo sexo nesse contexto está restrito ao ato sexual propriamente dito, desconsiderando aspectos socioculturais da sexualidade. De acordo com Chaveiro (2011), grande parte das pessoas entende a palavra sexualidade como sendo sinônimo de relaçáo sexual. No entanto, ao abordar o tema, outros fatores constituintes da sexualidade devem ser considerados, como aspectos psíquicos, sociais e culturais, distanciando-se do reducionismo biológico (Nogueira, Martins \& Rodrigues, 2012; Louro, 2013). Isto pode ser identificado nas perguntas enviadas pelos estudantes nas quais se identifica um claro atravessamento de questôes de poder, gênero, discriminação e violência.

Todavia, esta relação entre sexo e sexualidade é resultado de uma educação que ainda prioriza o corpo como um aparato puramente biológico. A abordagem fisiológica produz um tom de neutralidade e cientificidade sobre a complexidade de temas que, uma vez 
debatidos, podem desestabilizar tanto educadores como familiares. $\mathrm{O}$ tabu, que ainda envolve a sexualidade e a crença de que falar sobre o tema estimula a curiosidade e antecipa práticas sexuais, podem ser alguns dos aspectos relacionados ao desconforto em lidar com a temática.

Diferentes estudos demonstram que a sexualidade tem sido pouco discutida nos âmbitos familiar e escolar, seja devido à ausência de preparo dos pais e profissionais da educaçáo ou por tabus e preconceitos que necessitam ser desconstruídos (Camargo \& Ferrari, 2009; Hoffmann \& Zampieri, 2009). No campo das políticas públicas, assim como destacam de Oliveira Junior e Maio (2017), ocorre um "desagendamento" das temáticas relacionadas à sexualidade, como foi o caso do recuo do Ministério da Educação em relação às políticas Brasil sem Homofobia e Escola sem Homofobia.

Nesse contexto, houve náo somente um movimento de recolhimento da escola como um espaço de desenvolvimento para reflexão da importância de reconhecimento das diferenças, do respeito e inclusão, fundamentais para consolidação de cidadania e ética, como também houve o redirecionamento para a defesa de uma escola sem gênero. Segundo Mano (2017), esta seria uma tentativa de deixar a escola em uma suposta posição de neutralidade, como se esta posição já não representasse uma ideologia com referência a um determinado sujeito com mais direitos e poder que outros.

A partir da nuvem de palavras, observa-se que as palavras sexo, amor, homem, mulher, camisinha, gravidez e doenças, apesar de em princípio fazerem parte do repertório tradicional dos temas expostos dentro do contexto escolar, ainda se apresentam como campo de muitas dúvidas para os jovens. Este aspecto apareceu claramente nas rodas de conversas, o que nos faz pensar o quanto, mesmo no campo mais biológico, as escolas têm realmente se proposto a esclarecer dúvidas ou têm partido do princípio de que as informaçóes estão tão disponíveis que não é necessário abordá-las. Por outro lado, as temáticas trazidas pelos jovens não se restringiram a estas questóes, o que foi amplamente explorado nas oficinas.

Destaca-se que a palavra doença não está entre as primeiras mais citadas, o que pode indicar que a sexualidade entre jovens tem sido vista de forma menos ameaçadora e punitiva. Além disso, outras palavras indicam a complexidade de temáticas que paulatinamente estáo sendo introduzidas no repertório dos jovens por meio de outros meios de informação e experiências do cotidiano, tais como as questóes de gênero e prazer.

Logo, a educação sexual não deve envolver apenas conceitos relacionados ao ato sexual, mas explorar a sexualidade dentro de um enfoque sociocultural, abarcando a saúde reprodutiva, as relaçóes de gênero, as relaçóes interpessoais, o prazer corporal e a autoestima, posto que ela possui uma dimensão histórica, cultural, ética e política que abrange todo o sujeito (Santos, 2001; Gonçalves, Faleiro \& Malafaia, 2013), o que esteve muito presente nas discussóes realizadas com os alunos durante as oficinas. Pode-se constatar que essa ampliação da complexidade sobre a temática da sexualidade se apresenta tanto pela pulverização das palavras associadas (Figura 2), quanto pelas perguntas formuladas pelos alunos para a elaboraçáo das oficinas (Figura 3).

Nesse sentido, as dúvidas apresentadas pelos alunos explicitam os atravessamentos sociais e culturais que fazem parte de uma multiplicidade de experiências dos jovens. As perguntas se configuraram tanto por uma abordagem ampla e generalizada como, por exemplo, pela pergunta: "por que a maioria das gurias acha que os guris só pensam em sexo?”; como também por uma dúvida singularizada que trata de conflitos pessoais, a exemplo da pergunta: "sou virgem e me julgam, por quê?”.

A construçáo coletiva das oficinas a partir das perguntas permite a construção conjunta e favorece um alinhamento entre os valores dos adolescentes e as novas informaçôes acessadas, dando singularidade à sua compreensão da sexualidade e das futuras tomadas de decisão (Paiva, 2000). Sendo assim, introduzir a temática da sexualidade em uma roda de conversa entre jovens faz emergir conceitos e percepçóes transgeracionais, que colocados em pauta se transformam em questionamentos e reflexôes que podem ressignificar não só a compreensão de sua própria sexualidade, como produzir maior empatia para trajetórias diferentes da sua.

De acordo com os resultados da avaliação das oficinas, percebe-se que a maioria dos alunos considerou os assuntos conversados durante a oficina como muito importantes, o que mostra que, apesar de os jovens terem fácil acesso às informações, ainda consideram necessários espaços em que a sexualidade possa ser explorada e debatida livremente. Na mesma direção, mais da metade da amostra referiu que essas temáticas ainda não haviam sido faladas dentro do contexto escolar, em disciplinas regulares.

Por outro lado, apesar de menos da metade dos alunos ter afirmado possuir dúvidas sobre os assuntos abordados, a grande maioria alega ter saído mais informada após a oficina, e acredita ter esclarecido mitos e tabus que possuía sobre sexualidade. Diante desses resultados, é importante pensar sobre como ocorre a relação entre o acesso à informação sobre sexualidade 
e a apropriação da informação pelos jovens. $\mathrm{Na}$ atualidade, o fácil acesso à informaçáo e à tecnologia transmite uma percepção de conhecimento muito amplo sobre as diferentes temáticas que nos rodeiam. A partir de uma reflexão mais aprofundada, percebe-se que esse conhecimento é superficial, não dando conta da complexidade dos fenômenos envolvidos na constituição da sexualidade, o que ajuda na compreensão de haver uma pronta resposta da existência de conhecimento sobre os temas.

A falta de debate e reflexão sobre as pluralidades que envolvem a sexualidade contribui para o aumento de situações de discriminação, intolerância, exposição ao risco de IST, gravidez indesejada e a perpetuação de mitos associados à temática. As perguntas realizadas pelos estudantes denunciam um conhecimento limitado sobre os temas e ainda revelam, além das dúvidas, a vivência de preconceitos relacionados às relaçóes de dominação entre os diferentes marcadores sociais como classe social, raça/etnia e gênero (Figura 3). Nesse sentido, discutir temas de sexualidade também é discutir como se produzem as desigualdades sociais.

$\mathrm{O}$ acesso a informaçôes e educação em saúde sexual e reprodutiva, bem como a aquisição de métodos e alternativas para evitar uma gravidez e prevenção contra IST, é um direito do adolescente. No entanto, os jovens têm recebido poucas oportunidades para discutir a sexualidade e recebem uma educação sexual superficial, com informaçóes distorcidas, permeadas por tabus e preconceitos e insuficientes para a prevenção. Assim sendo, salienta-se a importância de intervençóes nas quais os jovens possam falar por eles mesmos, manifestando com suas palavras, gestos, sentidos e significados suas próprias realidades (Parker, 2000). Dessa forma, a disseminação de informaçôes coerentes influencia significativamente o autocuidado dos jovens, reduzindo condutas de risco (Freitas, 2012).

Destaca-se que a maior parte dos alunos se sentiu seguro e à vontade para falar sobre sexualidade ao longo da realizaçáo da oficina, o que pode ser decorrente do uso de uma linguagem de fácil compreensão associada ao conhecimento e segurança na condução da atividade. A linguagem utilizada partiu das perguntas elaboradas por eles mesmos, além de ser permeada por informalidade, sem a conotação de transmissão de informação, mas sim de debate e construçáo conjunta do conhecimento.

Outro ponto a ser mencionado é a necessidade de se romper com uma educação dita bancária (Freire, 2001), depositária de conhecimento, sem o comprometimento com a formaçáo de sujeitos autônomos em suas vivências afetivo-sexuais (Paiva, 2000). Entende-se que, para que os jovens adotem comportamentos de prevenção, é necessário que, além da transmissão de informaçóes, sejam fomentadas a reflexão e o diálogo (Madureira, Marques \& Jardim, 2010).

Percebe-se que a sexualidade segue restrita ao âmbito do privado e do segredo (Louro, 2013), e com isso mantêm-se as barreiras de circulação social da temática, dificultando uma politização das visóes vinculadas aos preconceitos, o que gera uma reprodução de antigos problemas. Os próprios estudantes se questionam sobre o silêncio das instituiçóes (família, escola) a respeito da sexualidade. Nesse sentido, a dificuldade de dialogar sobre esse tema pode estar relacionada ao fato de que o falar sobre a sexualidade do outro remete a questôes sobre a própria sexualidade.

A participação da família e da escola no processo de educação sexual dos adolescentes pode proporcionar esclarecimentos e reflexóes para que os jovens vivenciem sua sexualidade (Gonçalves et al., 2013). Essa educação sexual deve pressupor a busca de uma sexualidade emancipatória, isto é, uma sexualidade gratificante, socialmente livre e responsável, enriquecedora, compreendida como componente essencial da vida. A educação emancipatória (Garcia, 2005) implica no desenvolvimento de açôes educativas para a promoção da autonomia, buscando combater padróes de comportamentos estereotipados e hierarquizados, tabus e preconceitos.

Quanto à metodologia utilizada, a maioria dos estudantes achou o formato da oficina interessante $\mathrm{e}$ dinâmico, considerando esclarecedores tanto o método, quanto os recursos audiovisuais. Grande parte dos adolescentes acredita que a oficina afetará seus comportamentos positivamente. Esses resultados reforçam a potencialidade de intervençóes construídas a partir de oficinas para maior reflexão e participação ativa dos jovens nas atividades, podendo estimular comportamentos de autocuidado e promoção da saúde.

\section{CONSIDERAÇÓES FINAIS}

Considera-se necessária a existência de um espaço de circulação do tema da sexualidade, em que a fala livre e descontraída seja encorajada, já que esse conteúdo permeia a vida dos adolescentes. O compartilhamento de informaçóes em um espaço com liberdade de expressão e debate colabora para o desenvolvimento de uma postura mais crítica sobre os assuntos trabalhados, assim como contribui para o exercício de uma sexualidade mais saudável e responsável, diminuindo a quantidade de jovens em situação de vulnerabilidade, devido à ampliação de seu conhecimento e ao despertar para outras possibilidades de vida (Camargo \& Ferrari, 2009). 
Sendo assim, trabalhar sobre as questôes da sexualidade é uma importante intervençáo no campo da saúde pública, ao informar e sensibilizar o jovem para questôes de cuidado relacionadas às infecções sexualmente transmissíveis, HIV/aids e gravidez não planejada. Além disso, é um direito do adolescente que, ao convidá-lo ao diálogo, promove autonomia e responsabilidade no seu processo emancipatório, o que está de acordo com a efetivação dos direitos sexuais e reprodutivos. Nesse sentido, não há espaço para uma "neutralidade desagendada", pelo contrário, é necessária a integração de políticas públicas, universidades, escolas, famílias e jovens na construção de diálogos para promoção de respeito e cuidado consigo mesmo e com os outros.

Como alternativa de enfrentamento, considera-se importante fomentar uma nova abordagem por parte dos professores e também uma maior aproximação das famílias. Dessa forma, o desafio é encorajar e dar subsídios aos professores e familiares para a abertura de espaços em que possam ouvir as dúvidas e formas de pensar dos adolescentes, despojando-se da necessidade de serem prescritivos e normativos em relaçáo às condutas dos jovens. Portanto, intervençôes futuras com familiares e professores são necessárias para transversalizar o tema sobre a educaçáo sexual em diferentes contextos e também desmistificar o receio em falar sobre esse assunto.

\section{REFERÊNCIAS}

Bardin, L. (1977). Análise de conteúdo. Lisboa: Ediçóes 70.

Brasil (2010). Ministério da Saúde. Secretaria de Atenção em Saúde. Departamento de Ações Programáticas Estratégicas. Diretrizes nacionais para a atenção integral à saúde de adolescentes e jovens na promoção, proteção e recuperação da saúde. Brasília: Ministério da Saúde, 2010.

Brasil. (2016). Ministério da Saúde. Secretaria de Vigilância em Saúde. Departamento de DST, Aids e Hepatites Virais. Boletim Epidemiológico Aids e DST. Brasília: Ministério da Saúde. 64p.

Camargo, E. A. I., \& Ferrari, R. A. P. (2009). Adolescentes: conhecimentos sobre sexualidade antes e após a participação em oficinas de prevenção. Ciência \& Saúde Coletiva, 14(3), 937-946. Recuperado de http://www.scielo.br/pdf/csc/v14n3/30.pdf

Chaveiro, L. G. (2011). A temática sexualidade no contexto escolar: diagnóstico situacional na região leste de Goiânia, Goiás (Dissertação de mestrado). Faculdade de Enfermagem, UFG, Goiânia.
Recuperado de https://repositorio.bc.ufg.br/tede/ handle/tde/706

de Oliveira Júnior, I. B., \& Maio, E. R. (2017). "Não vai ser permitido a nenhum órgão do governo fazer propaganda de opçóes sexuais": o discurso inaugural no "desagendamento" do kit gay do MEC. Revista e-Curriculum, 15(1), 125-152. http://dx.doi. org/10.23925/1809-3876.2017v15i1p125-152

Figueiró, M. N. D. (2006). Educação sexual: como ensinar no espaço da escola. Revista Linhas, 7(1), online. Recuperado de http:// www.periodicos.udesc.br/index.php/ linhas/article/view/1323

Freire, P. (2001). Pedagogia da autonomia: saberes necessários à prática educativa. São Paulo, SP: Paz e Terra.

Freitas, K. R., \& Dias, S. M. Z. (2010). Percepçôes de adolescentes sobre sua sexualidade. Texto \& Contexto Enfermagem, 19(2), 351-357. Recuperado de http:// www.scielo.br/pdf/tce/v19n2/17.pdf

Freitas, D. L. (2012). Pressupostos de uma Formadora em Educação Sexual. Liçỗes da Prática. Que Rastros Temos Deixado Pelo Caminho? Contexto e Educação, 27(88), 35-61.

Garcia, A. M. (2005). A Orientação Sexual na Escola: Como os professores, alunos epais percebem a sexualidade e o papel da escola na orientação sexual (Dissertação de mestrado), Faculdade de Ciências, UNESP, São Paulo. Recuperado de http://repositorio.unesp.br/ handle/11449/90900

Gonçalves, R. C., Faleiro, J. H., \& Malafaia, G. (2013). Educaçáo sexual no contexto familiar e escolar: impasses e desafios. Holos, 5, 251-263. Recuperado de http://www2.ifrn.edu.br/ojs/index. $\mathrm{php} / \mathrm{HOLOS} /$ article/view/784

Hoffmann, A. C. O. S., \& Zampieri, M. F. M. (2009). A atuação do profissional da enfermagem na socialização de conhecimentos sobre sexualidade na adolescência. Rev. Saúde Pública, 2(1), 56-69. Recuperado de http://esp.saude.sc.gov.br/sistemas/ revista/index.php/inicio/article/viewFile/34/59

Jeolás, L. S., \& Ferrari, R. A. P. (2003). Oficinas de prevenção em um serviço de saúde para adolescentes: espaço de reflexáo e de conhecimento compartilhado. Ciência \& Saúde Coletiva, 8(2), 611620. Recuperado de http://www.scielo.br/pdf/csc/ v8n2/a21v08n2.pdf

Louro, G.L. (org, 2013). O corpo educado: pedagogias da sexualidade. Belo Horizonte: Autêntica.

Madureira, L., Marques, I. R., \& Jardim, D. P. (2010). Contracepção na adolescência: conhecimento 
e uso. Cogitare Enfermagem, 15(1), 100-105. Recuperado de http://revistas.ufpr.br/cogitare/ article/view/17179/11314

Mano, M. K. (2017). Da suspeição à suspensão: reflexôes sobre os caminhos recentes da democracia brasileira sob uma perspectiva de gênero. Ciência e Cultura, 69(1) , 34-38 . http://dx.doi. org/10.21800/2317-66602017000100014

Mantovani, G. D., Tres, B., Silva, R. M. M., \& Moura, C. B. (2014). Comparaçáo de dúvidas sobre sexualidade entre crianças e adolescentes. Contexto \& Educação, 29(92),72-90. Recuperado de https://www.revistas.unijui.edu.br/index.php/ contextoeducacao/article/view/2968/3622

Martins, C. B. G., \& Souza, S. P. S. (2013). Adolescente e Sexualidade: as possibilidades de um projeto de extensão na busca de uma adolescência saudável. Avances en Enfermería, 31(1), 170-176. Recuperado de http://www.scielo.org.co/pdf/aven/v31n1/ v31n1a16.pdf

Moizés, J. S., \& Bueno, S. M. V. (2010). Compreensão sobre sexualidade e sexo nas escolas segundo professores do ensino fundamental. Revista da Escola de Enfermagem da USP, 44(1), 205-212. Recuperado de http://www.scielo.br/pdf/reeusp/ v44n1/a29v44n1.pdf

Moskovics, J. M., \& Calvetti, P. U. (2008). Formação de multiplicadores para a prevençáo das DST/AIDS numa universidade espanhola. Psicologia: Ciência e Profissão, 28(1), 210217. Recuperado de http://www.redalyc.org/ articulo.oa?id=282021760016

Nogueira, M. J., Martins, A. M., \& Rodrigues, A. R. (2012). Escolas e unidades básicas de saúde: diálogos possíveis e necessários para a promoção da saúde sexual e reprodutiva dos adolescentes. Saúde em
Debate, 36(92), 117-124. Recuperado de http:// www.redalyc.org/pdf/4063/406341764014.pdf

Paiva, V. (2000). Fazendo arte com camisinha: sexualidades jovens em tempo de Aids. São Paulo: Summus.

Parker, R. (2000). Prefácio. In Paiva, V. Fazendo arte com a camisinha (pp. 13-17). São Paulo, SP: Sumus

Rocha, K. B., \& Pizzinato, A. (Producer). (2015). Você já pensou em fazer o teste rápido de HIV? [DVD]. Recuperado de https://www.youtube.com/ watch?v=giiMd2SwT6k

Santos, M. A. (2001). Orientação sexual no $1^{\circ}$ e $2^{\circ}$ ciclos do ensino fundamental: uma realidade distante? (Monografia). Faculdade de Pedagogia, UFRN, Rio Grande do Norte.

Silva, R. C. (2002). Metodologias participativas para trabalhos de promoção de saúde e cidadania. São Paulo, SP: Vetor.

Tonelli, M. J. F. (2004). Direitos sexuais e reprodutivos: algumas consideraçóes para auxiliar a pensar o lugar da psicologia e sua produção teórica sobre a adolescência. Psicologia \& Sociedade, 16(1), 151160. Recuperado de http://www.scielo.br/pdf/psoc/ v16n1/v16n1a13

UNAIDS (2016). Prevention Gap Report. Genebra: UNAIDS, 2016. Disponível em http://www.unaids. $\mathrm{org} / \mathrm{sites} /$ default/filesmedia_asset/2016-preventiongap-report_en.pdf

\section{Endereço para correspondência:}

Isabel Fernandes de Oliveira

Campus Universitário UFRN, Lagoa Nova

CEP: 59078-970 - Natal/RN

E-mail: fernandes.isa@uol.com.br

Recebido em 29/05/2017

Aceito em 15/09/2017 